\title{
BMJ Open Prevalence of sustained hypertension and obesity among urban and rural adolescents: a school-based, cross- sectional study in North India
}

\author{
Bishav Mohan, ${ }^{1}$ Amit Verma, ${ }^{1}$ Kavita Singh, ${ }^{2,3}$ Kalpana Singh, ${ }^{3}$ Sarit Sharma, ${ }^{4}$ \\ Raahat Bansal, ${ }^{1}$ Rohit Tandon, ${ }^{1}$ Abhishek Goyal, ${ }^{1}$ Bhupinder Singh, ${ }^{1}$ \\ Shibba Takkar Chhabra, ${ }^{1}$ Naved Aslam, ${ }^{1}$ Gurpreet Singh Wander, ${ }^{1}$ Ambuj Roy, ${ }^{5}$ \\ Dorairaj Prabhakaran ${ }^{2,3,6}$
}

To cite: Mohan B, Verma A, Singh K, et al. Prevalence of sustained hypertension and obesity among urban and rural adolescents: a schoolbased, cross-sectional study in North India. BMJ Open 2019;9:e027134. doi:10.1136/ bmjopen-2018-027134

- Prepublication history and additional material for this paper are available online. To view these files, please visit the journal online (http://dx.doi. org/10.1136/bmjopen-2018027134).

Received 14 October 2018 Revised 09 July 2019 Accepted 31 July 2019

Check for updates

(C) Author(s) (or their employer(s)) 2019. Re-use permitted under CC BY-NC. No commercial re-use. See rights and permissions. Published by BMJ.

For numbered affiliations see end of article.

Correspondence to

Dr Bishav Mohan;

bishav_68@yahoo.co.in

\section{ABSTRACT}

Objective Recent data on sustained hypertension and obesity among school-going children and adolescents in India are limited. This study evaluates the prevalence of sustained hypertension and obesity and their risk factors among urban and rural adolescents in northern India. Setting A school-based, cross-sectional survey was conducted in the urban and rural areas of Ludhiana, Punjab, India using standardised measurement tools. Participants A total of 1959 participants aged 11-17 years (urban: 849 ; rural: 1110) were included in this school-based survey.

Primary and secondary outcome measures To measure sustained hypertension among school children, two distinct blood pressure (BP) measurements were recorded at an interval of 1 week. High BP was defined and classified into three groups as recommended by international guidelines: (1) normal BP: $<90$ th percentile compared with age, sex and height percentile in each age group; (2) prehypertension: $\mathrm{BP}=90$ th-95th percentile; and (3) hypertension: BP >95th percentile. The Indian Academy of Pediatrics classification was used to define underweight, normal, overweight and obesity as per the body mass index (BMI) for specific age groups.

Results The prevalence of sustained hypertension among rural and urban areas was $5.7 \%$ and $8.4 \%$, respectively.

The prevalence of obesity in rural and urban school children was $2.7 \%$ and $11.0 \%$, respectively. The adjusted multiple regression model found that urban area (relative risk ratio (RRR): $1.7,95 \% \mathrm{Cl} 1.01$ to 2.93 ), hypertension (RRR: $7.4,95 \% \mathrm{Cl} 4.21$ to 13.16) and high socioeconomic status (RRR: $38.6,95 \% \mathrm{Cl} 16.54$ to 90.22 ) were significantly associated with an increased risk of obesity. However, self-reported regular physical activity had a protective effect on the risk of obesity among adolescents (RRR: $0.4,95 \% \mathrm{Cl} 0.25$ to 0.62 ). Adolescents who were overweight (RRR: $2.66,95 \% \mathrm{Cl} 1.49$ to 4.40 ) or obese (RRR: $7.21,95 \% \mathrm{Cl} 4.09$ to 12.70 ) and reported added salt intake in their diet (RRR: $4.90,95 \% \mathrm{Cl} 2.83$ to 8.48 ) were at higher risk of hypertension.

Conclusion High prevalence of sustained hypertension and obesity was found among urban school children and adolescents in a northern state in India. Hypertension among adolescents was positively associated with
Strengths and limitations of this study

- This study reports the prevalence of sustained hypertension, overweight and obesity among a large sample of school-going children from urban and rural areas of North India.

- Standardised blood pressure (BP) measurements at two separate occasions were recorded to detect the prevalence of sustained hypertension and avoid bias associated with 'point' estimates (single-time BP reading) of hypertension.

- The cross-sectional nature of our study, lack of cluster-level data analysis, and self-reporting of physical activity and salt intake data limited establishing a causal relation between high BP and obesity.

overweight and obesity (high BMI). Prevention and early detection of childhood obesity and high BP should be strengthened to prevent the risk of cardiovascular diseases in adults.

\section{INTRODUCTION}

High blood pressure (BP) and obesity among adolescents, in conjunction with many of their health consequences such as dyslipidaemia, abnormal plasma glucose and metabolic disorders, have dramatically increased over the past two decades worldwide due to the rapid socioeconomic, nutritional and epidemiological transitions. ${ }^{1}$ Early detection of these cardiovascular risk factors (hypertension and obesity) is an important public health priority as it may possibly prevent the adverse consequences of cardiovascular diseases in adulthood. ${ }^{12}$

Previous studies have reported varying prevalence of hypertension in children ranging from $<1 \%$ to $16.2 \%$ and the prevalence of obesity ranging from $12 \%$ to $19 \%$, which may be due to varying age groups selected for 
the study and the different criteria adopted for defining hypertension and obesity. ${ }^{3-9}$ In addition, dietary and cultural factors and significant variation in the prevalence of point and sustained hypertension could influence the varying prevalence of high $\mathrm{BP} .{ }^{10-14}$ In children and adolescents, the increasing rate of body mass index (BMI) is a strong predictor of adult levels of BP, insulin resistance and dyslipidaemia. Several studies have proposed an association between obesity and high BP, including increased cardiovascular risk factors. ${ }^{16915-18}$ A study conducted in North India 10 years ago showed a high prevalence of obesity (2.3\% urban and $3.6 \%$ rural areas) and hypertension $(6.7 \%$ urban and $2.6 \%$ rural areas) in adolescent population, with a significant increase in the prevalence of hypertension among overweight (15.3\% urban and $6.82 \%$ rural areas) and obese $(43.1 \%$ urban and $61.76 \%$ rural areas) population. ${ }^{16}$

However, current data in India regarding the changes in the prevalence of sustained hypertension and obesity and their association with cardiovascular risk factors are limited, particularly among children and adolescents from urban and rural areas. This study aimed to determine the prevalence of sustained hypertension and obesity and their risk factors among urban and rural adolescents aged 11-17 years in Ludhiana, North India.

\section{METHODS}

\section{Study design and setting}

Children were selected from urban and rural schools in and around Ludhiana, Punjab, a northern state in India. Since there are limited data available on the prevalence of overweight, obesity, prehypertension and hypertension from the developing northern states of India, Ludhiana, Punjab was selected as the study setting. Previously, in 2004 we conducted the first cross-sectional study in Ludhiana to determine the prevalence of obesity and hypertension among school children, which revealed a high prevalence of obesity (2.3\% urban and $3.6 \%$ rural areas) and hypertension (6.7\% urban and $2.6 \%$ rural areas). ${ }^{16}$ The present study is a repeated cross-sectional study, undertaken in the same urban and rural areas of Ludhiana, among school-going adolescents aged 11-17 years, between 15 March 2016 and 31 July 2017 (nearly after a decade of the first school survey).

\section{Selection of schools and study participants}

The Ludhiana district has a total of 1864 schools, out of which 317 are in the urban and 1547 are in the rural areas. We selected schools by simple random sampling strategy, considering the population proportion to sample size, and within the $2 \mathrm{~km}$ vicinity of the schools which were included in the first cross-sectional study conducted in 2004. We then used a stratified sampling strategy to select children (adolescents) aged 11-17 years in a given school, considering each class as strata and equally dividing the required sample size for that school among all the classes.
From each class, the students were again selected by simple random sampling method.

The study inclusion criteria were all children/adolescents aged 11-17 years, both sexes, and belonging to urban and rural schools selected to participate in the study. Children having chronic illnesses, endocrine problems (to avoid secondary causes of hypertension and obesity), physical or mental disabilities (prediagnosed), and those who did not provide written informed consent were excluded from the study.

Data were collected using a pretested questionnaire meeting the objective of the study. A validated questionnaire was used to collect the data on socioeconomic status (modified BG Prasad Scale), dietary habits (including added salt intake) and physical activity. Informed consent and assent statements were taken from the parents of all children before conducting the school survey and BP measurements. The age of the school children was obtained from the school records. The name and other particulars were entered in a pretested proforma. Appropriate permission from the head of the institution (school principal) was obtained prior to examining the school children.

\section{Anthropometric assessments}

Height was measured by making the child stand upright, barefoot, on the ground, with heels, buttocks and shoulder touching the wall, and with the head in Frankfurt plane. Height was measured using a sliding stadiometer calibrated to an accuracy of $0.1 \mathrm{~mm}$. Weight was recorded using a spring balance calibrated to an accuracy of $0.5 \mathrm{~kg}$. BMI was calculated using the standard formula, weight $(\mathrm{kg}) /$ height $\left(\mathrm{m}^{2}\right)$, and values were compared with the WHO growth charts. BMI classification was also performed according to the Indian Academy of Pediatrics revised growth charts (table 1 ).

\section{BP assessment}

BP was measured between 08:00 and 11:00 after giving a rest of $10 \mathrm{~min}$. BP was recorded by field investigators, with the children in sitting position, both their hands resting on the examining table and the cubital fossa supported at the level of the heart.

The field investigators were given formal training on how to measure proper BP in children, using cuff of appropriate sizes. We used a BP apparatus (Rudolf Riester, Bruckstr, Germany) with appropriate paediatric cuffs. BP was measured after applying an appropriate-sized cuff on the right arm encircling two-thirds circumference of the

Table 1 Body mass index classification for children aged 5-18 years as per the Indian Academy of Pediatrics

\begin{tabular}{ll}
\hline Underweight & $<3$ rd adult equivalent line \\
Normal & $3 r d-23 r d$ adult equivalent line \\
Overweight & $>23$ rd adult equivalent line \\
Obese & $>27$ th adult equivalent line \\
\hline
\end{tabular}


arm with the lower edge being $2.5 \mathrm{~cm}$ above the cubital fossa (as per the WHO guidelines). BP was measured on the right arm for consistency and compared with standard tables. BP was recorded as per the American Heart Association guidelines. ${ }^{17}$ Systolic blood pressure (SBP) was determined as the appearance of the first Korotkoff sounds, and diastolic blood pressure (DBP) was taken at the point of muffling of heart sounds (fourth Korotkoff sounds). Three measurements were taken at an interval of $5 \mathrm{~min}$ each, and an average of these readings was taken as the average SBP and DBP. To measure sustained hypertension among school children, a second BP measurement was taken after an interval of at least 1 week of the first BP measurements. Children were then classified into three groups as recommended by the guidelines ${ }^{18}$ :

- BP <90th percentile: normal BP (compared with age, sex and height percentile in each age group).

- $\mathrm{BP}=90$ th-95th percentile: prehypertension.

- $\mathrm{BP}>95$ th percentile: hypertension.

\section{Patient and public involvement}

This cross-sectional survey among school-going children did not involve patients in the design of the study. We shared the BP and BMI values with the study participants (school children and their guardians). We also provided handouts on the risk factors of obesity and hypertension to all study participants, and a guest lecture on practising healthy lifestyle was given by a physician from the Dayanand Medical College and Hospital, Ludhiana. In addition, appropriate referrals were made to the nearby healthcare providers for children detected with high BP, overweight and obese BMI values.

\section{Sample size calculation}

The prevalence of hypertension in school children in the same catchment area was previously found to be $6.7 \%$ in urban and 2.6\% in rural areas in $2004 .{ }^{16}$ In our previous study, the prevalence of obesity was calculated as $14 \%$ and $9 \%$ in urban and rural school children, respectively. ${ }^{16}$ The sample size for the current survey was calculated using OpenEpi V.3.03 software, using the prevalence of obesity at $80 \%$ power and $5 \%$ level of significance. The required sample for both urban and rural areas was 678 .

\section{Statistical analyses}

Analyses were performed using Stata V.13 software. Continuous variables (age, weight, height, BMI, SBP and $\mathrm{DBP}$ ) were used to describe the general characteristics of the school children with mean and SD, and the means were then compared for sex differences and area differences using a Student's t-test. $\chi^{2}$ test was used to determine the age-specific and sex-specific proportion (prevalence) difference between rural and urban areas for hypertension and BMI status. Multinomial logistic regression model was constructed for BP status (no hypertension, prehypertension and hypertension) and BMI status (underweight, normal, overweight and obesity) to report the associations (relative risk ratio) of sociodemographic (age, sex and socioeconomic status) and health-related factors (BMI, BP, dietary habits, added salt intake, junk food intake and physical activity). Multinomial logistic regression models were adjusted for all sociodemographic and health-related factors. Hosmer and Lemeshow test was used to see the goodness of fit of the models, and Akaike information criterion (AIC) value to check the best model. All statistical test values were two-sided, and a p value of less than 0.05 was considered to indicate statistical significance.

\section{RESULTS}

The study included a total of 1959 participants, comprising $1110(54.1 \%$ girls $)$ and $849(43.3 \%$ girls $)$ adolescents aged 11-17 years from rural and urban schools, respectively. Table 2 presents that characteristics of study participants. Overall, $8.6 \%$ of boys were overweight and obese compared with $10.5 \%$ and $4.1 \%$ of girls who were overweight and obese, respectively. A higher proportion of participants who were overweight and obese $(12.1 \%$ boys and $15.5 \%$ girls who were overweight; $13.3 \%$ boys and $8.4 \%$ girls who were obese) were from the urban schools versus rural schools $(5.3 \%$ boys and $7.5 \%$ girls who were overweight; $4.1 \%$ boys and $1.5 \%$ girls who were obese). Overall $6.2 \%$ boys and $7.2 \%$ girls were found to have sustained hypertension. Adolescents belonging to the middle socioeconomic class $(73.2 \%$ boys; $69.8 \%$ girls $)$ were greater in the urban schools while those belonging to the low socioeconomic class $(58.5 \%$ boys; $54.6 \%$ girls) were greater in the rural schools, measured according to the modified BG Prasad Scale. There was a predominance of vegetarian children ( $48.5 \%$ boys; $69.7 \%$ girls) in rural schools as compared with urban schools. Added salt intake in the diet of rural children $(58.9 \%$ boys; $58.6 \%$ girls) was slightly lower than the urban children $(64.9 \%$ boys; $60.1 \%$ girls). Furthermore, the intake of junk food in rural ( $83.1 \%$ boys; $76.7 \%$ girls) schools was lower than in urban schools ( $95.6 \%$ boys; $91.6 \%$ girls).

Table 3 shows that children with prehypertension and hypertension had significantly higher BMI (overweight or obesity) than their normotensive counterparts. In urban schools, students with normal BMI, are overweight and obese had sustained prevalence of hypertension: $4.9 \%$ $(n=45), 13.9 \%(n=10)$ and $26.7 \%(n=8)$, respectively. In rural schools, the prevalence of hypertension was $4.9 \%$ $(n=30), 9.6 \%(n=11)$ and $31.6 \%(n=30)$ among students with normal BMI, are overweight and obese, respectively. Both rural and urban students with hypertension had higher added salt in food: $8.1 \%$ and $12.2 \%$, respectively. Intake of junk food was more in urban students with hypertension when compared with their rural counterparts $(8.7 \%$ vs $5.8 \%)$, compared with children with normal BP.

Table 4 shows the mean SBP among rural and urban school children. The mean SBP $(\mathrm{mm} \mathrm{Hg})$ of hypertensive, prehypertensive and normotensive population was significantly higher among urban school children than 
Table 2 Characteristics of study participants by rural/urban schools and sex

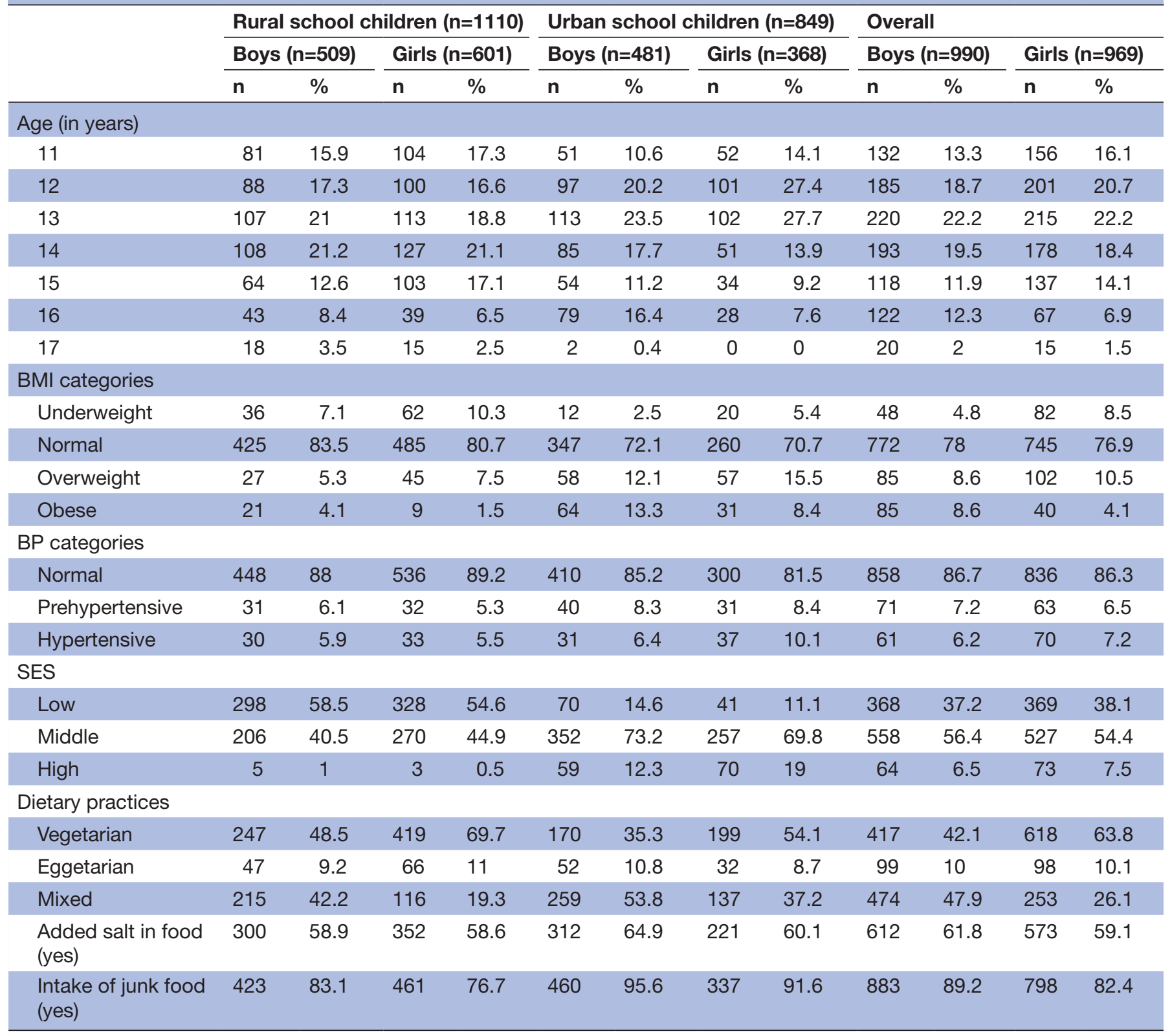

BMI, body mass index; BP, blood pressure; SES, socioeconomic status.

their rural counterparts: 134.3 vs $132.4(\mathrm{p}=0.03) ; 122.6 \mathrm{vs}$ 121.3 ( $p=0.02)$; and 110.4 vs 105.5 ( $p<0.001)$, respectively.

Figure 1 demonstrates the association between the prevalence of hypertension and prehypertension according to the BMI percentiles. There is an increase in the prevalence of hypertension in both rural and urban population with increasing BMI.

Table 5 demonstrates the adjusted risk ratio (RR) of risk factors for prehypertension and hypertension. Participants who were overweight (RR: 2.56, 95\% CI 1.49 to 4.40 ), obese (RR: $7.21,95 \%$ CI 4.09 to 12.7 ) and who reported added salt intake in their diet (RR: 4.90, $95 \%$ CI 2.83 to 8.48 ) were at higher risk for hypertension, whereas regular physical activity reduced prehypertension risk (RR: $0.63,95 \%$ CI 0.42 to 0.94 ). The goodness of fit of our final adjusted model was checked by Hosmer and Lemeshow test, and because the test was not significant $(p=0.64)$ we were satisfied with the fit of our model, with the AIC value for this model being 1777.9.

Table 6 presents the adjusted risk ratio for the underweight overweight and obesity. The adjusted multinomial regression model found that urban area (RR: 1.72, 95\% CI 1.01 to 2.93 ), hypertension (RR: $7.44,95 \% \mathrm{CI} 4.21$ to 13.16) and high socioeconomic status (RR: 38.6, 95\% CI 16.54 to 90.22$)$ significantly increased the risk for obesity. However, self-reported regular physical activity had a protective effect on the risk of obesity among adolescents (RR: $0.39,95 \%$ CI 0.25 to 0.62 ). The goodness of fit was not significant in this model $(\mathrm{p}=0.52)$ and the AIC value of this model was 2693.8. 
Table 3 Prevalence of hypertension and prehypertension among rural/urban school children

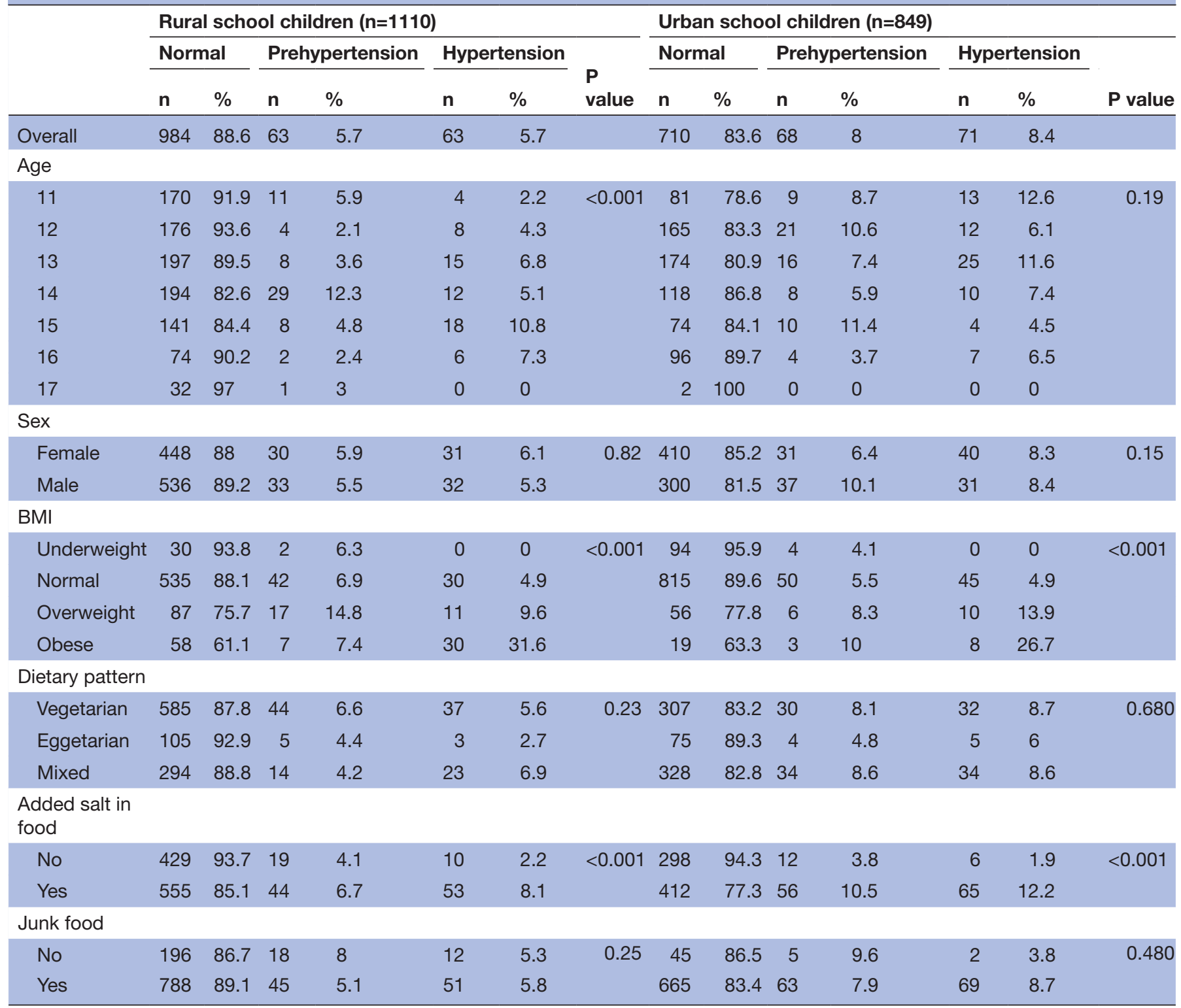

BMI, body mass index.

Table 4 Mean systolic and diastolic blood pressure by urban/rural school children

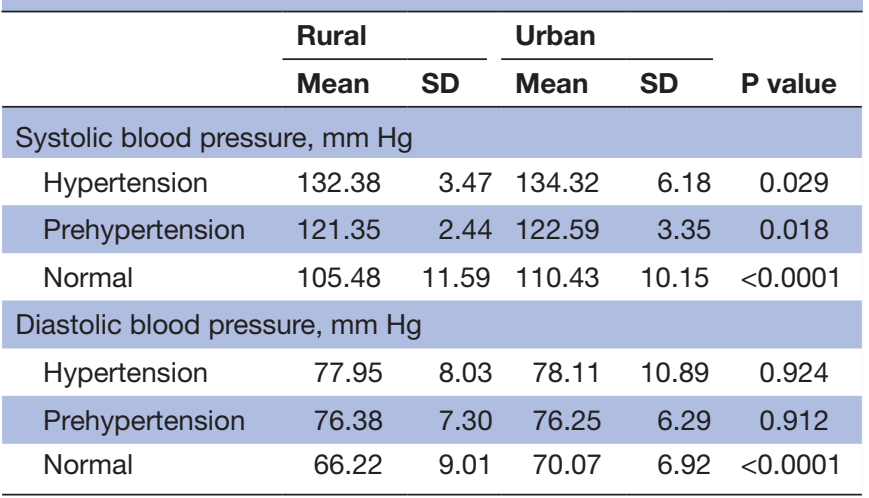

p-value $<0.05$ considered as statistically significant.
(Unadjusted relative risk ratio for the risk factors for prehypertension, hypertension, underweight, overweight and obesity is presented in online supplementary etable 1.)

\section{DISCUSSION}

In this school-based, repeat cross-sectional study, we found a high prevalence of sustained hypertension in rural $(5.7 \%)$ and urban $(8.4 \%)$ school children. In rural children with hypertension, the prevalence of overweight and obesity was $12.5 \%$ and $28 \%$, respectively, while among urban children with hypertension the prevalence of overweight and obesity was $10.1 \%$ and $31.2 \%$, respectively. The prevalence of hypertension and obesity among school children in the present study was significantly higher than the previous survey conducted in 

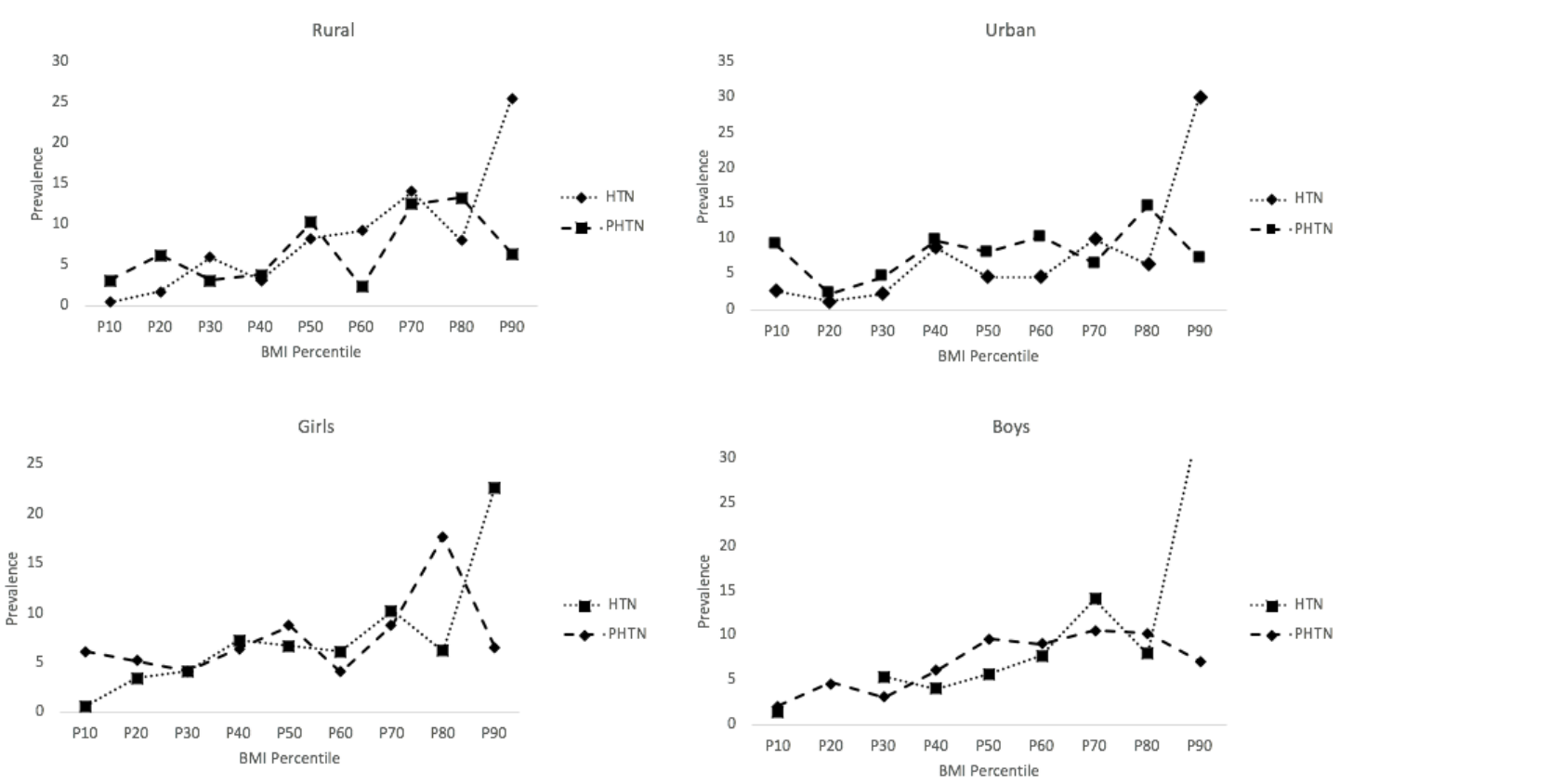

Figure 1 Prevalence of hypertension and prehypertension according to body mass index percentiles.

$2004^{18}$ in the same area, which showed the prevalence of sustained hypertension to be $2.6 \%$ and $6.7 \%$ in rural and urban school children, respectively, and prevalence of overweight and obesity of $4.7 \%$ and $3.6 \%$ in rural areas and $11.6 \%$ and $2.3 \%$ in urban areas, respectively (online supplementary etable 2).

Furthermore, the mean SBP and DBP of children with hypertension of both urban and rural population were significantly higher than the SBP and DBP of their normotensive counterparts, as was also noticed in the previous study. ${ }^{16}$

Our study results are consistent with previous studies of the prevalence of hypertension and obesity among school children and adolescents who have shown a rise in high BP and obesity with age. Previous reports of hypertension prevalence among school children and adolescents have reported a range from $1.0 \%$ to $16.2 \%$, which might include a high incidence of 'point' hypertension (defined as transient hypertension, ie, when BP measurement is taken only once to classify hypertension). ${ }^{9}{ }^{1019-23}$ Many researchers have argued that serial measurement of $\mathrm{BP}$ is crucial to determine the prevalence of sustained hypertension, that is, persistent elevations in BP. In our study, the prevalence of sustained hypertension in urban children was $8.4 \%$, which is relatively higher when compared with other studies reporting a prevalence of $0.5 \%-2 \% .{ }^{24}{ }^{25}$ A similar cross-sectional study conducted in the same region almost a decade ago showed a prevalence of sustained hypertension of $6.7 \% .^{16}$ The high prevalence of sustained hypertension in our study could be attributed to the rapid socioeconomic, demographic and nutritional transitions, leading to an epidemic of cardiovascular diseases. There is a twofold to threefold increase in the prevalence of sustained hypertension among both urban and rural school children compared with previous cross-sectional survey conducted in the same region in
2004, which could be attributed to rapid urbanisation in rural areas. ${ }^{16}$ Also, there is a significant increase in the prevalence of obesity $\left(\mathrm{BMI}>30 \mathrm{~kg} / \mathrm{m}^{2}\right.$ ) in our present study compared with the previous survey.

Evidence suggests that children from affluent families are more overweight and obese because of a sedentary lifestyle, physical inactivity, altered eating habits and increased fat content in their diet. ${ }^{26}{ }^{27}$ High BP among overweight and obese children may occur due to excessive salt intake, increased steroid production, increased cardiac output and alteration in the reception of various pressor substances. ${ }^{28}$ In our study, the prevalence of sustained hypertension increased from $4.6 \%$ with normal BMI to $12.5 \%$ in overweight children and $28.0 \%$ in obese children. Similar increasing trend in hypertension was observed with higher BMI levels in rural children. ${ }^{26} 2729$ Notably, a small proportion of rural children were hypertensive with normal BMI, which supports the relationship of hypertension with increasing BMI (and among overweight and obese children). The influence of BMI was stronger on SBP than DBP in both girls and boys. We demonstrated that SBP and DBP increased across the entire range of BMI and were not defined by a threshold.

In our study we found that a higher BMI was associated with increasing BP values, corroborating findings from previous research studies. However, causality between high BMI and increased BP cannot be established due to the cross-sectional nature of the present study. Furthermore, various studies had reported that the link between childhood obesity and hypertension is contentious. ${ }^{30-34}$ For example, Chiolero $e t a l^{30}$ have argued that compared with the epidemic of childhood obesity over the last two decades, the BP level has not risen proportionately. Additionally Wang et $a \vec{l}^{33}$ reported that there was no relationship between adiposity and DBP among adolescents (12-18 years) from rural areas in China. ${ }^{33}$ The disparities 
Table 5 Adjusted risk ratio for the risk factors for prehypertension and hypertension

\begin{tabular}{|c|c|c|c|c|}
\hline & \multicolumn{2}{|c|}{ Prehypertension } & \multicolumn{2}{|c|}{ Hypertension } \\
\hline & RRR & $95 \% \mathrm{Cl}$ & RRR & $95 \% \mathrm{Cl}$ \\
\hline \multicolumn{5}{|l|}{ Age } \\
\hline 12 & 0.73 & (0.39 to 1.37 ) & 0.64 & (0.31 to 1.29$)$ \\
\hline 13 & 0.64 & (0.34 to 1.21$)$ & 1.11 & (0.59 to 2.11$)$ \\
\hline 15 & 0.90 & (0.46 to 1.79$)$ & 1.42 & (0.70 to 2.87$)$ \\
\hline $16-17$ & $0.38^{*}$ & (0.15 to 0.93$)$ & 0.99 & (0.45 to 2.22$)$ \\
\hline \multicolumn{5}{|l|}{ Sex } \\
\hline Male & 1 & (1.00 to 1.00$)$ & 1 & (1.00 to 1.00$)$ \\
\hline Female & 1.09 & (0.74 to 1.61$)$ & 1.15 & (0.77 to 1.73$)$ \\
\hline \multicolumn{5}{|l|}{ BMI categories } \\
\hline Normal & 1 & (1.00 to 1.00$)$ & 1 & (1.00 to 1.00$)$ \\
\hline Underweight & 0.70 & (0.29 to 1.65$)$ & - & - \\
\hline Overweight & $1.94^{*}$ & (1.16 to 3.25$)$ & $2.56^{\star \star \star}$ & (1.49 to 4.40$)$ \\
\hline Obese & 1.28 & (0.59 to 2.80$)$ & $7.21^{\star \star \star}$ & (4.09 to 12.70 ) \\
\hline \multicolumn{5}{|l|}{ SES } \\
\hline Low & 1 & (1.00 to 1.00$)$ & 1 & (1.00 to 1.00$)$ \\
\hline Middle & 1.07 & (0.68 to 1.68$)$ & 1.02 & (0.62 to 1.66$)$ \\
\hline \multicolumn{5}{|l|}{ Junk food } \\
\hline Yes & $2.37^{\star \star \star}$ & (1.54 to 3.63 ) & $4.90^{\star \star \star}$ & (2.83 to 8.48$)$ \\
\hline \multicolumn{5}{|l|}{ Dietary pattern } \\
\hline Vegetarian & 1.04 & (0.70 to 1.55$)$ & 0.83 & (0.56 to 1.25$)$ \\
\hline Eggetarian & 0.80 & (0.38 to 1.69$)$ & 0.79 & (0.36 to 1.74$)$ \\
\hline \multicolumn{5}{|l|}{ Exercise } \\
\hline No & 1 & (1.00 to 1.00$)$ & 1 & (1.00 to 1.00$)$ \\
\hline Yes & $0.63^{*}$ & (0.42 to 0.94$)$ & 0.70 & (0.47 to 1.06$)$ \\
\hline
\end{tabular}

Adjusted risk ratio for hypertension was estimated using multinomial logistic regression model and included age, sex, BMI and all other variables shown in the table. The goodness-of-fit test of the model was not significant $(p=0.636)$ and the AIC value was 1777.9 . ${ }^{*} \mathrm{P}<0.01,{ }^{* *} \mathrm{p}<0.001,{ }^{* * *} \mathrm{p}<0.0001$.

$\mathrm{AIC}$, akaike information criterion; BMI, body mass index; RRR, relative risk ratio; SES, socioeconomic status.

in the socioeconomic status, dietary habits, exercise levels and measurements of adiposity and BP (single measure vs sustained BP) among children/adolescents could influence the variations in results (ie, association between BMI and BP) observed in the previous studies. ${ }^{31} 34$

This study has important limitations. First, the study being restricted to urban and rural areas of the Ludhiana district in Punjab (northern state in India) may not be generalisable across India. Second, given the cross-sectional survey design, the causal relationship between high BP and obesity cannot be established. Third, our study was limited by the self-reported measures of physical activity and added salt intake in diet and lack of blood parameters such as fasting blood glucose and lipids. Cluster-level data analysis 
Table 6 Adjusted risk ratio for the risk factors for body mass index

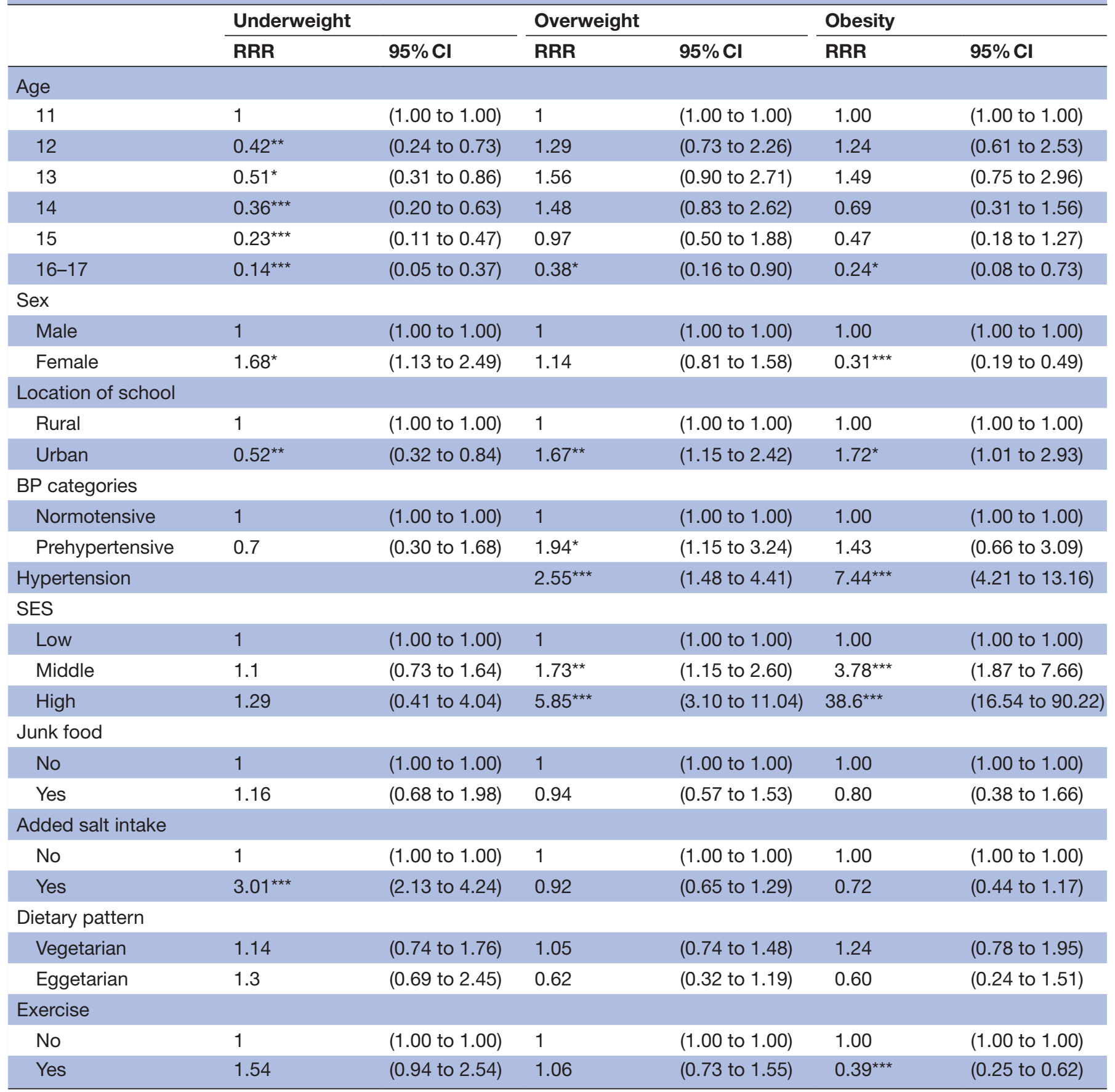

Adjusted risk ratios for BMI categories were estimated using ordinal logistic regression model and included age, sex, BP and all other variables shown in the table. The goodness-of-fit test of the model was not significant $(p=0.524)$ and the AIC value was 2693.8 . ${ }^{\star} \mathrm{P}<0.01,{ }^{* \star} \mathrm{p}<0.001,{ }^{\star \star *} \mathrm{p}<0.0001$.

$\mathrm{AIC}$, akaike information criterion; BMI, body mass index; BP, blood pressure; RRR, relative risk ratio; SES, socioeconomic status.

and macro-level changes in the population such as socioeconomic transition, urbanisation and influence of health policies were not accounted for in the multinomial logistic regression model to demonstrate the association between hypertension/obesity and its associated risk factors.

However, the increasing prevalence rates of hypertension and obesity found in our study are alarming as we know obesity in children is associated with an increased incidence of hypertension, diabetes, metabolic syndrome, coronary heart disease, and an overall increase in morbidity and mortality during adult life.

\section{CONCLUSION}

High prevalence of sustained hypertension and obesity was found among school-going adolescents in a northern 
state in India. Hypertension among adolescents was positively associated with obesity (high BMI). Prevention and early detection of childhood and adolescent obesity and high BP should be strengthened to prevent the risk of metabolic syndrome and cardiovascular diseases in adulthood.

\section{Author affiliations}

${ }^{1}$ Cardiology, Hero DMC Heart Institute, Ludhiana, , India

${ }^{2}$ Centre for Chronic Conditions and Injuries, Public Health Foundation of India, Gurgaon, Haryana, India

${ }^{3}$ Clinical Trials Unit, Centre for Chronic Disease Control, New Delhi, Delhi, India

${ }^{4}$ Dayanand Medical College and Hospital, Ludhiana, India

${ }^{5}$ Cardiology, All India Institute of Medical Sciences, New Delhi, India

${ }^{6}$ London School of Hygiene and Tropical Medicine, London, UK

Contributors The manuscript was prepared by BM, AV and KavS. KalS assisted with statistical data analysis. BS, AV and SS assisted with primary data collection. All other authors (RB, RT, AG, STC, NA, GSW, AR and DP) contributed significantly to reviewing the manuscript and provided technical inputs. All authors have reviewed and approved this version of the manuscript for submission to the journal.

Funding The authors have not declared a specific grant for this research from any funding agency in the public, commercial or not-for-profit sectors.

Competing interests None declared.

Patient consent for publication Not required.

Ethics approval The study was approved by the Research and Ethics Committee of Dayanand Medical College and Hospital (approval reference number: $\mathrm{DMCH} / 4 / 78-2015)$.

\section{Provenance and peer review Not commissioned; externally peer reviewed.}

Data availability statement Data are available upon reasonable request from the corresponding author.

Open access This is an open access article distributed in accordance with the Creative Commons Attribution Non Commercial (CC BY-NC 4.0) license, which permits others to distribute, remix, adapt, build upon this work non-commercially, and license their derivative works on different terms, provided the original work is properly cited, appropriate credit is given, any changes made indicated, and the use is non-commercial. See: http://creativecommons.org/licenses/by-nc/4.0/.

\section{REFERENCES}

1. Turer CB, Brady TM, de Ferranti SD. Obesity, hypertension, and dyslipidemia in childhood are key modifiable antecedents of adult cardiovascular disease. Circulation 2018;137:1256-9.

2. Beilin L, Huang R-C. Childhood obesity, hypertension, the metabolic syndrome and adult cardiovascular disease. Clin Exp Pharmacol Physiol 2008;35:409-11.

3. Armstrong KR, Cote AT, Devlin AM, et al. Childhood obesity, arterial stiffness, and prevalence and treatment of hypertension. Curr Treat Options Cardiovasc Med 2014;16.

4. Basiratnia M, Derakhshan D, Ajdari S, et al. Prevalence of childhood obesity and hypertension in South of Iran. Iran J Kidney Dis 2013;7:282-9.

5. Ip P, Ho FKW, So H-K, et al. Socioeconomic gradient in childhood obesity and hypertension: a multilevel population-based study in a Chinese community. PLoS One 2016;11:e0156945.

6. Pastucha D, Talafa V, Malincikova J, et al. Obesity, hypertension and insulin resistance in childhood - a pilot study. Biomedical Papers 2010;154:77-81.

7. Sabo RT, Lu Z, Daniels S, et al. Serial childhood BMI and associations with adult hypertension and obesity: the Fels longitudinal study. Obesity 2012;20:1741-3.

8. Virdis A, Ghiadoni L, Masi S, et al. Obesity in the childhood: a link to adult hypertension. Curr Pharm Des 2009;15:1063-71.

9. Wühl E. Hypertension in childhood obesity. ActaPaediatrica 2018.
10. Akbari M, Moosazadeh M, Ghahramani S, et al. High prevalence of hypertension among Iranian children and adolescents. J Hypertens 2017;35:1155-63.

11. Ejike CECC. Prevalence of hypertension in Nigerian children and adolescents: a systematic review and trend analysis of data from the past four decades. J Trop Pediatr;30:fmw087.

12. Okpokowuruk FS, Akpan MU, Ikpeme EE. Prevalence of hypertension and prehypertension among children and adolescents in a semi-urban area of Uyo Metropolis, Nigeria. Pan Afr Med J 2017;28.

13. Ebrahimi $\mathrm{H}$, Emamian $\mathrm{MH}$, Hashemi $\mathrm{H}$, et al. Prevalence of prehypertension and hypertension and its risk factors in Iranian school children. J Hypertens 2018;36:1816-24.

14. Hirschler V, Molinari C, Gonzalez C, et al. Prevalence of hypertension in Argentinean Indigenous children living at high altitudes versus US children. Clin Exp Hypertens 2018;40:752-7.

15. Zhao $Y$, Wang $L$, Xue $H$, et al. Fast food consumption and its associations with obesity and hypertension among children: results from the baseline data of the childhood obesity study in China Megacities. BMC Public Health 2017;17.

16. Mohan B, Kumar N, Aslam N, et al. Prevalence of sustained hypertension and obesity in urban and rural school going children in Ludhiana. Indian Heart J 2004;56:310-4.

17. Perloff D, Grim C, Flack J, et al. Human blood pressure determination by sphygmomanometry. Circulation 1993;88:2460-70.

18. Flynn JT, Kaelber DC, Baker-Smith CM, et al. Clinical practice guideline for screening and management of high blood pressure in children and adolescents. Pediatrics 2017;140:e20171904.

19. Beltrán-Sánchez H, Crimmins EM, Teruel GM, et al. Links between childhood and adult social circumstances and obesity and hypertension in the Mexican population. $J$ Aging Health 2011;23:1141-65.

20. Sharma A, Bhattad S, Kumar P. Prevalence of hypertension \& prehypertension among school children. Indian J Med Res 2016;143.

21. Badeli $H$, Hassankhani A, Naeemi Z, et al. Prevalence of hypertension and obesity-related hypertension in urban school-aged children in Rasht. Iran J Kidney Dis 2016;10:364-8.

22. Lu Y, Luo B, Xie J, et al. Prevalence of hypertension and prehypertension and its association with anthropometrics among children: a cross-sectional survey in Tianjin, China. J Hum Hypertens 2018;32:789-98.

23. Chiolero A, Paccaud F, Bovet P. Pre-hypertension and hypertension among adolescents of Switzerland. J Pediatr 2007;151:e24-5.

24. Hari P, Bagga A, Srivastava RN. Sustained hypertension in children. Indian Pediatr 2000;37:268-74.

25. Arar MY, Hogg RJ, Arant BS, et al. Etiology of sustained hypertension in children in the southwestern United States. Pediatr Nephrol 1994:8:186-9.

26. Raj M, Sundaram KR, Paul M, et al. Body mass index trend and its association with blood pressure distribution in children. $J$ Hum Hypertens 2010;24:652-8.

27. Raj M, Sundaram KR, Paul M, et al. Obesity in Indian children: time trends and relationship with hypertension. Natl Med J India 2007;20:288-93.

28. Yamani MH, Massie BM. Hypertension, myocardial ischemia, and sudden death. Curr Opin Cardiol 1994:9:542-50.

29. Hu J, Chu G-ping, Huang F-fei, et al. Relation of body mass index (BMI) to the prevalence of hypertension in children: a 3 years' school-based prospective study in Suzhou, China. Int J Cardiol 2016;222:270-4.

30. Chiolero A, Bovet P, Paradis G, et al. Has blood pressure increased in children in response to the obesity epidemic? Pediatrics 2007:119:544-53.

31. Chiolero A, Madeleine G, Gabriel A, et al. Prevalence of elevated blood pressure and association with overweight in children of a rapidly developing country. J Hum Hypertens 2007;21:120-7.

32. Willig AL, Casazza K, Dulin-Keita A, et al. Adjusting adiposity and body weight measurements for height alters the relationship with blood pressure in children. Am J Hypertens 2010;23:904-10.

33. Wang $\mathrm{H}$, Necheles $\mathrm{J}$, Carnethon M, et al. Adiposity measures and blood pressure in Chinese children and adolescents. Arch Dis Child 2008;93:738-44.

34. Chiolero A, Peytremann-Bridevaux I, Paccaud F. Associations between obesity and health conditions may be overestimated if selfreported body mass index is used. Obesity Reviews 2007;8:373-4. 